\title{
Dementia Diagnoses and Treatment in Geriatric Ward Patients: A Cross-Sectional Study in Poland
}

This article was published in the following Dove Press journal:

Clinical Interventions in Aging

\author{
Zyta Beata Wojszel (1D ${ }^{1,2}$ \\ 'Department of Geriatrics, Medical \\ University of Bialystok, Bialystok, Poland; \\ ${ }^{2}$ Department of Geriatrics, Hospital of \\ the Ministry of Interior in Bialystok, \\ Bialystok, Poland
}

Purpose: The study aimed to determine the prevalence of dementia, its types, and treatment in geriatric ward patients.

Patients and Methods: A cross-sectional study of 406 patients $(77.8 \%$ women, median age 82, IQR (77-86) years) who underwent a comprehensive geriatric assessment in one of the Polish hospitals between September 2014 and April 2015 was conducted.

Results: Dementia was diagnosed in 132 (32.5\%) patients (46\% mixed dementia; 32\% Alzheimer's disease; 10\%vascular dementia; 5\% dementia in Parkinson's disease; 4\% frontotemporal; 3\% atypical parkinsonism). A total of $95(72 \%)$ dementia cases were not detected before, and in the above half of these patients, it was not mentioned in the referral document. Only $33.3 \%$ of dementia patients were on cognitive enhancers (donepezil, rivastigmine, or memantine); $36.4 \%$ received antipsychotics, $45.5 \%$ received anti-depressants, $25.8 \%$ received nootropics, and $16.7 \%$ received anxiolytics/hypnotics.

Discussion: The results confirmed the high incidence of underdiagnoses and undertreatment of dementia in patients admitted to the geriatric ward. It is partly due to the lack of systematic cognitive assessment in primary care settings, although other factors can play a role.

Keywords: comprehensive geriatric assessment, geriatric ward, dementia diagnosis, dementia treatment, anti-dementia medications, cognitive enhancers, psychotropic medications, antipsychotics, anti-depressants, underdiagnoses, undertreatment

\section{Summary}

- There is no reliable data on the prevalence and treatment of dementia in the population of older people burdened with chronic diseases and disability in Poland.

- This cross-sectional study of 406 older patients admitted to the geriatric ward found a $32 \%$ prevalence of dementia, and only one-third was detected before admission and treated. High use of neuroleptics and anti-depressants was found, significantly higher in previously diagnosed dementia.

- Research on a representative sample of community-dwelling older people is needed to evaluate the situation of dementia diagnosis and treatment in Poland.

\section{Introduction}

Dementia is one of the most common psychogeriatric syndromes associated with significant morbidity and mortality, ${ }^{1,2}$ and nursing home placement risk. ${ }^{3}$ Due to the aging of the population, the disease burden of dementia in developed countries is
Correspondence: Zyta Beata Wojsze

Department of Geriatrics, Medical

University of Bialystok, Fabryczna Str. 27,

Bialystok |5-47|, Poland

$\mathrm{Tel}+48858694982$

Email wojszel@umb.edu.pl
Clinical Interventions in Aging 2020:15 2183-2194

(c) (i) (5) 2020 Wojzzel. This work is published and licensed by Dove Medical Press Limited. The full terms of this license are available at https:///www.dovepress.com/terms.php you hereby accept the Terms. Non-commercial uses of the work are permitted without any further permission from Dove Medical Press Limited, provided the work is properly attributed. For permission for commercial use of this work, please see paragraphs 4.2 and 5 of our Terms (https://www.dovepress.com/terms.php). 
still growing, as age is one of the main risk factors of cognitive deterioration. It is projected that in the next decades, the number of persons suffering from dementia will rise considerably in many developed and developing countries. ${ }^{4-7}$ In many countries, there is still the problem of late detection of dementia and too little appropriate therapy implementation. ${ }^{8-12}$ Although no systematic screening for dementia in the general population is recommended, ${ }^{13}$ it is emphasized, that assessing cognitive performance ought to be the inherent part of a comprehensive geriatric assessment. ${ }^{14}$ Some studies support the diagnosis of dementia in very elderly patients with multiple comorbidities, as influencing their prognosis and quality of life. ${ }^{11,15,16}$

There is no reliable data on the prevalence and incidence of dementia in the Polish population. In the last nationwide multidisciplinary study on aging in Poland - the PolSenior study carried out in 2008-2012 - some attention was paid to the prevalence of cognitive deterioration in the communitydwelling older people. ${ }^{17,18}$ Cognitive abilities in the representative sample of people aged $65+$ years were estimated in this project based on the Mini-Mental State Examination (MMSE). Only $31.6 \%$ of the studied sample had the MMSE score above 27 points; in $36.3 \%$ of the cases, the score was within the range of 24-27 points (treated as mild cognitive impairment), and $38 \%$ of participants had the score below 24 points - suggestive for dementia. Unfortunately, no attempt was made in the PolSenior study to provide an indepth and reliable assessment of the prevalence of dementia, its causes, and treatment. Nevertheless, the study revealed that the use of cognitive enhancers in Poland's elderly population is negligible. That could be the result of either too rare diagnosing dementia by doctors or a consequence of the high cost of anti-dementia therapy in this period. Earlier research, carried out over 20 years ago by Gabryelewicz and co-workers (based on a questionnaire screening and more in-depth cognitive assessment), revealed quite similar dementia rates in Warsaw to those found in other European studies. ${ }^{19}$ However, in these times, there was little awareness of the issue of dementia in Poland and virtually no access to antidementia medicatons.

There was no research carried out and recently published that could provide information on how the situation looks like nowadays in Poland - not only on the prevalence of dementia but also on its diagnosis and treatment. The study presented in this paper attempts to - at least partially - fill this gap. The aim of this study, conducted among patients aged $60+$ hospitalized in one of the geriatric wards in Poland, was to determine the prevalence of dementia and its types, the treatment with anti-dementia drugs at admittance and discharge from the ward, and the usage of other psychotropic medications in a population highly burdened with co-morbidity and disability.

\section{Patients and Methods}

\section{Research Site}

The geriatrics ward is located in a 159-bed hospital - one of the four multidisciplinary hospitals in Bialystok. The Department of Geriatrics of the Medical University of Bialystok is located here. It has 17 beds and provides care to inhabitants of rural and urban areas of the Podlaskie region in north-eastern Poland, one of the demographically oldest Polish provinces. Bialystok city, with above 300000 inhabitants, is its capital.

The department of geriatrics is a subacute ward. Older people with multimorbidity and physical and/or cognitive disabilities are admitted mainly in a planned manner. The average waiting time for admission to the ward is approximately 3 months. A comprehensive geriatric assessment by the multidisciplinary team is performed during the patients' hospital stay. It aimes to identify reasons for patients' functional decline, diagnose geriatric syndromes, and reduce polypharmacy.

\section{Participants}

A total of 416 consecutive patients admitted to the ward between September 2014 and April 2015 were included in the analysis but due to the limited availability of detailed data on pharmacotherapy before admittance in 10 cases, the final analysis was carried out in 406 patients. It was a secondary analysis of data collected during the cross-sectional study on frailty and multimorbidity in patients of the Department of Geriatrics (Hospital of the Ministry of Interior and Administration in Bialystok, Poland). ${ }^{20}$ Patients' enrollment to the study groups is presented on Figure 1.

\section{Measures and Procedure}

The data were collected retrospectively based on patients' paper and electronic hospital health records. Data collected included information on patient's age, gender, place of residence (urban/rural; community-dwelling/nursing home), way of living (alone/with others), years of education, history of hospitalizations in the previous year, the prevalence of 14 chronic diseases (atrial fibrillation, 


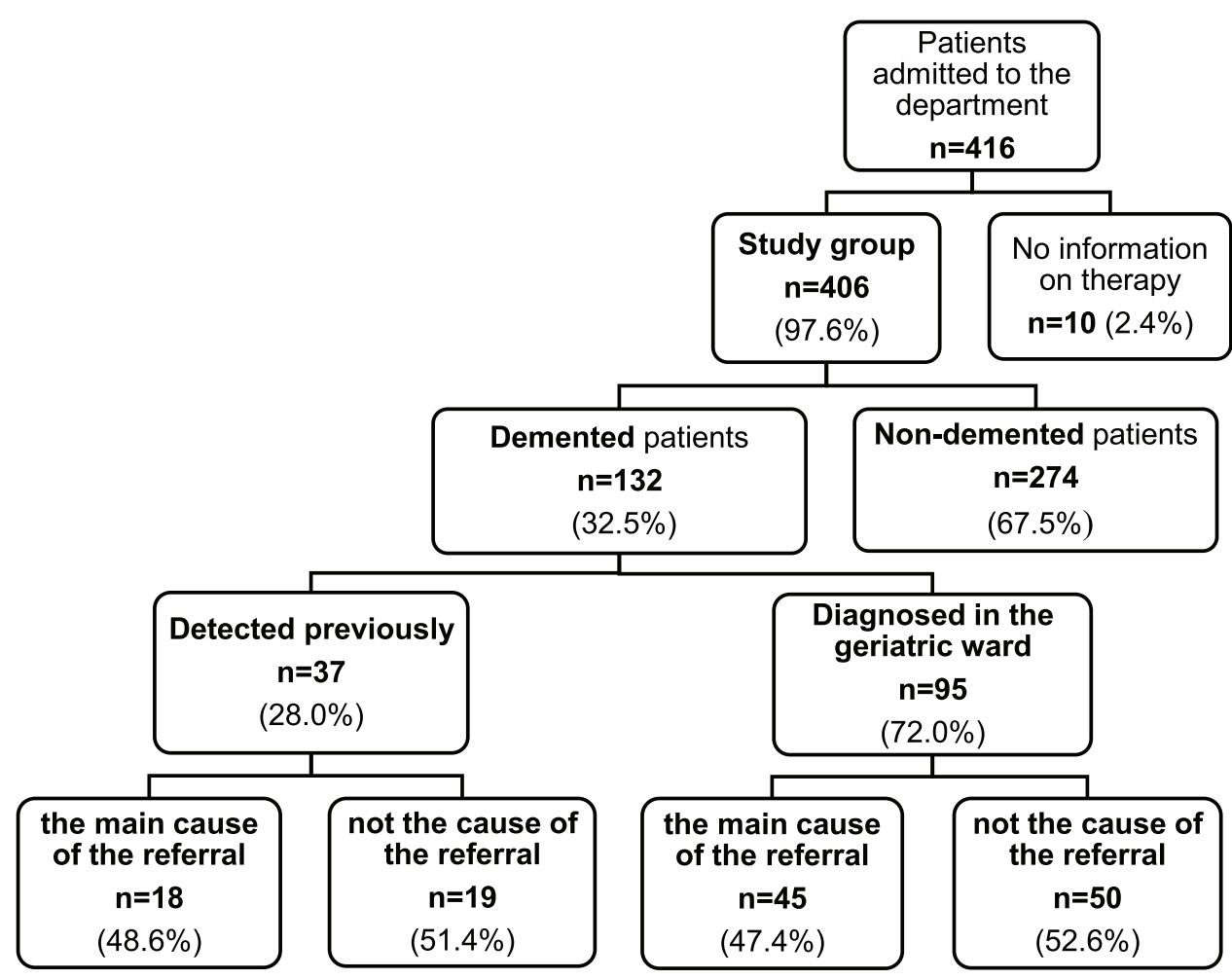

Figure I Patients' enrolment to the study.

chronic arthritis, chronic cardiac failure, chronic obstructive pulmonary disease, chronic renal disease, diabetes/ prediabetes, hypertension, ischemic heart disease, myocardial infarction, neoplasm, osteoporosis, parkinsonism, peripheral arterial disease, and stroke), and medications taken before hospitalization. Five or more drugs taken were treated as "polypharmacy", and five or more diseases of 14 listed - as "multimorbidity". The main reason for the referral to the geriatric ward (according to the ICD 10 classification) was extracted from the referral document, and information on hospital length of stay was gathered.

Patients diagnosed with dementia at discharge were classified as the dementia group and the rest of the participants as the non-dementia group. The assessment process for dementia at the geriatrics department includes a few consecutive steps. It starts with cognitive screening with the Abbreviated Mental Test Score (AMTS) in all patients admitted to the department. ${ }^{21}$ In subjects with an abnormal AMTS result or with memory complaints, or with behavioral disturbances history collected from the patient's caregiver, assessment with MMSE is performed.${ }^{22}$ Additionally to the row result of the MMSE, a score adjusted for age and years of education, according to Mungas and co-corkers' correction, is calculated. ${ }^{23}$ The in-depth neuropsychological evaluation is performed only if a patient is referred with suspected dementia, when the patient and/or their caregivers report memory problems and behavioral disorders or when the result of the cognitive screening tests performed on admission is abnormal. In some cases, this diagnosis is postponed (patients with depression, delirium). Dementia was classified into six subtypes based on the international criteria: Alzheimer's disease (AD); vascular dementia (VaD); mixed dementia of $\mathrm{AD}$ and $\mathrm{VaD}$ (MD); frontotemporal dementia (FTD); dementia associated with Parkinson's disease (PDD); and dementia in atypical parkinsonism (APD) ${ }^{24,25}$

The results of comprehensive geriatric assessment taken into account in the analysis included the ability to perform activities of daily living (ADL) assessed with the Barthel Index, ${ }^{26} 6$ instrumental ADL items of Duke OARS scale (IADL), ${ }^{27}$ and frailty status evaluation with the seven items Canadian Study of Health and Aging Clinical Frailty Scale (CFS), ${ }^{28}$ the score of 6 or 7 of CFS was classified as severe frailty.

Psychotropic medications received by the patient before admittance were categorized according to the Anatomical Therapeutic Chemical (ATC) Classification System: antipsychotics (N05A), anxiolytics (N05B), hypnotics/sedatives 
(N05C), anti-depressants (N06A), anticonvulsants (N03), anti-dementia drugs (N06D), and anti-vertigo (N07). ${ }^{29,30}$ Additionally, information on taking peripheral vasodilators and lipid modifying agents was also gathered. For antidementia medications, also information on prescription at discharge was collected.

\section{Data Analysis}

Analyses were done with IBM SPSS Version 18 Software suit (SPSS, Chicago, IL, USA). The variables' distribution was checked with Shapiro-Wilk tests. They were presented as frequency and percentage (categorical variables), as means and standard deviation (normally distributed quantitative variables), or as medians and interquartile range (not normally distributed quantitative variables). Proportions were compared using $\chi 2$ tests, while the Student's $t$-test for independent samples and MannWhitney $U$-test were used to compare means and medians. Relative risks (RRs) with confidence intervals (CIs) were calculated to evaluate the potential risk factors that might influence the occurrence of dementia in geriatric inpatients. Differences between two dependent samples were assessed with Wilcoxon signed-rank test. In all analyses, a two-tailed $\mathrm{P}$ value of less than 0.05 was regarded as significant. Analyses did not include missing data.

\section{Ethics Approval}

The source study was approved by the Ethics Committee at the Medical University of Bialystok (no R-I-002/305/ 2013). All procedures performed in the study were in accordance with the ethical standards of the Medical University of Bialystok research committee and with the Helsinki declaration and its later amendments. The study can be classified as a study of "usual practice". All study participants gave their informed consent to participate in it. Secondary analysis of data did not require additional approval.

\section{Results}

\section{Demographics and Clinical}

\section{Characteristics}

Demographics and clinical characteristics of the study group are presented in Table 1. The median age in the study group was 82 (IQR, 77-86) years. Most of the participants were at the age of 75 or more $(84.2 \%)$, female (77.8\%), living in the urban area $(78.8 \%)$, communitydwelling (96.8\%), and living with others (70.3\%). More than half of them did not complete primary school. The study group was highly burdened with multimorbidity and polypharmacy. Hypertension, ischemic heart disease, chronic cardiac failure, atrial fibrillation, diabetes, chronic osteoarthritis, and chronic kidney disease were especially common.

Diseases of the circulatory system (34\%), mental and behavioural disorders $(22.2 \%)$, and diseases of the musculoskeletal system and connective tissue (11.1\%) were the most frequent causes of the referral to the geriatric department. Dementia as the main ICD-10 diagnosis was the cause of the referral in $18.5 \%$ of the hospitalized patient ( $47.7 \%$ diagnosed with dementia and $4.4 \%$ of non-dementia patients). In patients for which dementia was not confirmed, the alternative diagnoses at discharge included depression combined with the bad general health status (4 cases), depression (3 cases), diabetes/hypoglycemia (3 cases), and mild cognitive impairment ( 2 cases). The median of the hospital stay was 8 (IQR, 5-9) days, and did not differ between dementia and non-dementia group. The vast majority of patients $(96.3 \%)$ were discharged home, 3 patients $(0.7 \%)$ died, $8(2 \%)$ were transferred to another hospital/ward for further treatment (eg, due to stroke or acute coronary syndrome), and 4 (1\%) were transferred to a long-term care institution.

\section{Dementia Diagnosis and Memory}

\section{Complaints}

Of the 406 subjects, 132 (32.5\%) were dementia patients and the other 274 (67.5\%) served as controls (Table 1). In $37(28 \%)$ of dementia cases, the diagnosis of dementia was established before admission. In the next $60.6 \%$ of them, memory complaints or behavioral disturbances before hospitalization were confirmed in the history taken (contrary to $10.9 \%$ in non-dementia cases, $\mathrm{P}<0.001$ ). In 2 cases of dementia diagnosed and treated before hospital stay, the diagnosis was finally excluded after the neuropsychologist's assessment - an alternative diagnosis was depression, and anti-depressants were prescribed for these patients.

The most frequent dementia type was the MD, observed in 61 (45.9\%) cases. AD was diagnosed in 43 $(32.3 \%)$ cases and $\mathrm{VaD}$ in $13(9.8 \%)$ cases. Less frequently PDD $(n=7 ; 5.3 \%)$, APD $(n=4 ; 3.0 \%)$, and FTD $(n=5$; $3.8 \%$ ) were observed (Figure 2).

Patients with dementia were significantly older, more frequently male, and less frequently living alone. As it was 
Table I Demographics and Clinical Characteristics of Sample

\begin{tabular}{|c|c|c|c|c|c|c|}
\hline & \multirow{2}{*}{ Total } & \multicolumn{2}{|c|}{ Dementia Diagnosis } & \multirow{2}{*}{$\operatorname{RR}(95 \% \mathrm{Cl})$} & \multirow{2}{*}{$\begin{array}{l}P \\
\text { values }^{\mathbf{a}}\end{array}$} & \multirow{2}{*}{$\begin{array}{l}\text { Missing } \\
\text { Data }\end{array}$} \\
\hline & & Yes & No & & & \\
\hline n (\%) & $406(100.0)$ & $132(32.5)$ & $274(67.5)$ & & & \\
\hline \multicolumn{7}{|l|}{ Demographics } \\
\hline Age, y, Me (IQR) & $82(77-86)$ & $83(78-88)$ & $82(76-86)$ & & 0.008 & \\
\hline Age, $75+$ years, $n(\%)$ & $342(84.2)$ & $121(91.7)$ & $221(80.7)$ & $2.1(1.2-3.6)$ & 0.002 & \\
\hline Sex, women, n (\%) & $316(77.8)$ & $93(70.5)$ & $223(8 \mid .4)$ & $0.7(0.5-0.9)$ & 0.02 & \\
\hline Living in long term care, $\mathrm{n}(\%)$ & $13(3.2)$ & $5(3.8)$ & $8(2.9)$ & $1.2(0.6-2.4)$ & 0.76 & \\
\hline Living alone, n (\%) & $116(29.7)$ & $30(22.7)$ & $86(33.2)$ & $0.7(0.5-0.98)$ & 0.04 & \\
\hline Living in rural area, $\mathrm{n}(\%)$ & $86(21.2)$ & $23(17.4)$ & $63(23.0)$ & $0.8(0.5-1.2)$ & 0.24 & \\
\hline Years of education, Me (IQR) & $7(6-11)$ & $7(5-11)$ & $7(6-11)$ & & 0.28 & 59 \\
\hline Length of hospital stay, Me (IQR) & $8(5-9)$ & $8(6-10)$ & $7(5-9)$ & & 0.13 & \\
\hline \multicolumn{7}{|l|}{ Main reason of hospitalization (according to the ICD-I0 code) } \\
\hline Neoplasms, n (\%) & $4(1.0)$ & $2(1.5)$ & $2(0.7)$ & & & \\
\hline Diseases of blood and blood forming organs, $n$ (\%) & $20(4.9)$ & I (0.8) & $19(6.9)$ & & & \\
\hline Endocrine, nutritional and metabolic diseases, $\mathrm{n}(\%)$ & $33(8.1)$ & $8(6.1)$ & $25(9.1)$ & & & \\
\hline Mental and behavioural disorders, $\mathrm{n}(\%)$ & $90(22.2)$ & $67(50.8)$ & $23(8.4)$ & & & \\
\hline Diseases of the nervous system, $\mathrm{n}(\%)$ & $31(7.6)$ & $13(9.8)$ & $18(6.6)$ & & & \\
\hline Diseases of the circulatory system, $n(\%)$ & $138(34.0)$ & $26(19.7)$ & $112(40.9)$ & & & \\
\hline Diseases of the respiratory system, $\mathrm{n}(\%)$ & $2(0.5)$ & I (0.8) & $\mathrm{I}(0.4)$ & & & \\
\hline Diseases of the digestive system, $n(\%)$ & $8(2.0)$ & $3(2.3)$ & $5(1.8)$ & & & \\
\hline Diseases of the skin and subcutaneous tissue, $n(\%)$ & $4(1.0)$ & $2(1.5)$ & $2(0.7)$ & & & \\
\hline Diseases of the musculoskeletal system and connective tissue, $\mathrm{n}(\%)$ & $45(11.1)$ & $3(2.3)$ & $42(15.3)$ & & & \\
\hline Diseases of the genitourinary system, $\mathrm{n}(\%)$ & $8(2.0)$ & I $(0.8)$ & $7(2.6)$ & & & \\
\hline $\begin{array}{l}\text { Symptoms, signs and abnormal clinical and laboratory findings, not } \\
\text { elsewhere classified, } n(\%)\end{array}$ & $21(5.2)$ & $5(3.8)$ & $16(5.8)$ & & & \\
\hline \multicolumn{7}{|l|}{ Dementia status at admittance } \\
\hline Diagnosed dementia, n (\%) & $37(9.1)$ & $37(28.0)$ & $2(0.7)$ & $3.9(3.9-4.6)$ & $<0.001$ & \\
\hline Dementia as the main ICD-10 diagnosis in the referral letter, $\mathrm{n}(\%)$ & $75(18.5)$ & $63(47.7)$ & $12(4.4)$ & $4.1(3.2-5.4)$ & $<0.001$ & \\
\hline $\begin{array}{l}\text { Memory problems/behavioural disturbances as the leading complaint, } \\
\mathrm{n}(\%)\end{array}$ & $110(27.1)$ & $80(60.6)$ & $28(10.2)$ & $4.1(3.2-5.4)$ & $<0.001$ & \\
\hline \multicolumn{7}{|l|}{ Cognitive abilities } \\
\hline AMTS, Me (IQR), N=37I & $8(6-9)$ & $\begin{array}{l}5(3-7) \\
n=113\end{array}$ & $\begin{array}{l}9(7-10) \\
n=258\end{array}$ & & $<0.001$ & \\
\hline MMSE, $M(S D), N=|8|$ & $20.18(5.6)$ & $\begin{array}{l}16.73(4.6) \\
n=95\end{array}$ & $\begin{array}{l}23.99(3.9) \\
\mathrm{n}=86\end{array}$ & & $<0.001$ & 225 \\
\hline MMSE cor., $M(S D), N=157$ & $22.68(4.7)$ & $\begin{array}{l}19.8(3.8) \\
\mathrm{n}=86\end{array}$ & $\begin{array}{l}26.14(3.3) \\
n=71\end{array}$ & & $<0.001$ & 249 \\
\hline \multicolumn{7}{|l|}{ Chronic diseases } \\
\hline Number of chronic diseases, Me (IQR) & $4(3-6)$ & $4(3-6)$ & $4(3-6)$ & & 0.79 & \\
\hline Multimorbidity, n (\%) & $195(40.8)$ & $64(48.5)$ & $|3|(47.8)$ & $1.01(0.8-1.3)$ & 0.92 & \\
\hline Hypertension, n (\%) & $319(78.6)$ & $98(74.2)$ & $221(80.7)$ & $0.8(0.6-1.1)$ & 0.16 & \\
\hline Ischemic heart disease, $\mathrm{n}(\%)$ & $221(54.4)$ & $67(50.8)$ & $154(56.2)$ & $0.9(0.7-1.1)$ & 0.34 & \\
\hline Myocardial infarction, n (\%) & $39(9.6)$ & $15(11.4)$ & $24(8.8)$ & $1.2(0.8-1.8)$ & 0.47 & \\
\hline Chronic cardiac failure, $\mathrm{n}(\%)$ & $160(39.4)$ & $44(33.3)$ & $116(42.3)$ & $0.8(0.6-1.04)$ & 0.08 & \\
\hline Atrial fibrillation, $\mathrm{n}(\%)$ & $96(23.6)$ & $35(26.5)$ & $61(22.3)$ & $1.2(0.9-1.6)$ & 0.38 & \\
\hline Peripheral arterial disease, $\mathrm{n}(\%)$ & $61(15.0)$ & $30(22.7)$ & $31(11.3)$ & $1.7(1.2-2.3)$ & 0.004 & \\
\hline Stroke/TIA, n (\%) & $56(13.8)$ & $27(20.5)$ & $29(10.6)$ & $1.6(1.2-2.2)$ & 0.009 & \\
\hline Parkinsonism, n (\%) & $54(13.3)$ & $32(24.2)$ & $22(8.0)$ & $2.1(1.6-2.8)$ & $<0.001$ & \\
\hline Diabetes, n (\%) & $126(31.0)$ & $44(33.3)$ & $82(29.9)$ & I.I (0.8-1.5) & 0.49 & \\
\hline Neoplasm, n (\%) & $31(7.6)$ & $8(6.1)$ & $23(8.4)$ & $0.8(0.4-1.4)$ & 0.55 & \\
\hline COPD, n (\%) & $42(10.3)$ & $8(6.1)$ & $34(12.4)$ & $0.6(0.3-1.1)$ & 0.06 & \\
\hline
\end{tabular}

(Continued) 
Table I (Continued).

\begin{tabular}{|c|c|c|c|c|c|c|}
\hline & \multirow[t]{2}{*}{ Total } & \multicolumn{2}{|c|}{ Dementia Diagnosis } & \multirow[t]{2}{*}{$\mathbf{R R}(95 \% \mathrm{Cl})$} & \multirow{2}{*}{$\begin{array}{l}P \\
\text { values }^{\mathbf{a}}\end{array}$} & \multirow{2}{*}{$\begin{array}{l}\text { Missing } \\
\text { Data }\end{array}$} \\
\hline & & Yes & No & & & \\
\hline Chronic osteoarthritis, n (\%) & $319(78.6)$ & $90(68.2)$ & $229(83.6)$ & $0.6(0.4-0.8)$ & 0.001 & \\
\hline Osteoporosis, n (\%) & $73(18.0)$ & II (8.3) & $62(22.6)$ & $0.4(0.2-0.7)$ & $<0.001$ & \\
\hline Chronic kidney disease, $n(\%)$ & $216(53.2)$ & $75(56.8)$ & $|4|(5 \mid .5)$ & $1.2(0.9-1.5)$ & 0.34 & \\
\hline Hospitalization in the last year, $n(\%)$ & $120(29.8)$ & $36(27.5)$ & $84(30.9)$ & $0.9(0.7-1.2)$ & 0.56 & \\
\hline \multicolumn{7}{|l|}{ Drugs at admittance } \\
\hline Number of drugs, Me (IQR) & $7(5-9)$ & $7(4-10)$ & $7(5-9)$ & & 0.16 & \\
\hline Polypharmacy, n (\%) & $321(79.1)$ & $98(74.2)$ & $223(81.4)$ & $0.8(0.6-1.0)$ & 0.12 & \\
\hline \multicolumn{7}{|l|}{ Functional abilities } \\
\hline Barthel Index, Me (IQR) & $90(70-100)$ & $75(45-95)$ & $95(80-100)$ & & $<0.001$ & 6 \\
\hline IADL, Me (IQR) & $7(3-11)$ & $3(0-8)$ & $8(6-12)$ & & $<0.001$ & 10 \\
\hline Clinical Frailty Scale, Me (IQR) & $5(4-5.25)$ & $5(4-6)$ & $4(4-5)$ & & $<0.001$ & \\
\hline Severe frailty, $n(\%)$ & $101(24.9)$ & $54(40.9)$ & $47(17.2)$ & $2.1(1.6-2.7)$ & $<0.001$ & \\
\hline Urinary incontinence, $\mathrm{n}(\%)$ & $191(47.6)$ & $77(58.3)$ & $114(42.4)$ & $1.5(1.2-2.0)$ & 0.003 & \\
\hline Faecal incontinence, $\mathrm{n}(\%)$ & $52(12.9)$ & $31(23.5)$ & $21(7.8)$ & $2.1(1.6-2.7)$ & $<0.001$ & \\
\hline
\end{tabular}

Notes: ${ }^{a}$ Mann-Whitney test (continuous or interval variables) and $\chi^{2}$ test (categorical variables). Significant values are bolded and defined by a two-tailed $\mathrm{P}<0.05$. Abbreviations: AMTS, Abbreviated Mental Test Score; Cl, confidence interval; COPD, chronic obstructive pulmonary disease; IADL, instrumental activities of daily living; IQR, inter-quartile ranges; M, mean; Me, median; MMSE, Mini-Mental State Examination; MMSE cor, MMSE result adjusted for age and years of education according to Mungas and co-workers; $n$, number of cases; RR, relative risk; SD, standard deviation; TIA, transient ischaemic attack.

expected, they performed significantly worse in cognitive abilities testing (AMTS, row, and corrected MMSE). In 35 cases, AMTS was not available because patients' health status did not allow them to perform testing. Dementia sufferers significantly more frequently were diagnosed with peripheral arterial disease, history of stroke/transient ischemic attack (TIA), and parkinsonism but significantly less frequently with chronic osteoarthritis and osteoporosis. There were no differences between dementia and nondementia groups in the prevalence of hypertension, ischemic heart disease, myocardial infarction, chronic cardiac failure, atrial fibrillation, diabetes, neoplasm, COPD, and chronic kidney disease. The groups did not differ in the number of drugs taken before admission, the prevalence of polypharmacy, and hospitalizations in the last 12 months. Dementia patients were significantly more seriously dependent on others in personal and instrumental ADL and were more severely frail and significantly more frequently reported urinary and fecal incontinence (Table 1).

\section{Cognitive Abilities}

As expected, patients with dementia differed significantly in the results achieved in the screening tests of cognitive abilities from patients without such diagnosis (Table 1). The median value of the AMTS score, the mean values of the MMSE, and the corrected MMSE scores were significantly lower in dementia sufferers.

In dementia patients, MMSE was performed in 95 cases in 20 patients previously diagnosed and in 75 diagnosed during hospitalization. Both groups did not differ in the MMSE score $(16.1 \pm 4.8$ versus $16.89 \pm 4.6$, respectively, $\mathrm{P}=0.50$ ). In 86 dementia cases, the corrected result of the MMSE was available. In dementia previously diagnosed and diagnosed during hospital stay, the corrected scores were also similar (18.56 \pm 3.5 versus $20.2 \pm 3.8, \mathrm{P}=0.11$ ). A total of $50 \%$ diagnosed during the hospital stay patients had MMSE score $<17$ points and corrected MMSE score $<20$ points so dementia was diagnosed only in the moderate or the more severe phase. The reasons for missing MMSE in "dementia" group included: aphasia -3 cases, advanced dementia in patients with very limited cognition - 11 cases, severe general health status not allowing for cognitive status assessment -5 cases, patients with dementia previously diagnosed and not reassessed during a hospital stay - 17 cases, and unknown reason -1 case. It is also worth mentioning that the MMSE score did not differ significantly between patients referred to the hospital with the ICD 10 code of dementia and those without such a diagnosis in the referral letter (Figure 3).

\section{Anti-Dementia Treatment}

Only one-third of dementia patients received cognitive enhancers before hospitalization (Table 2). The most 


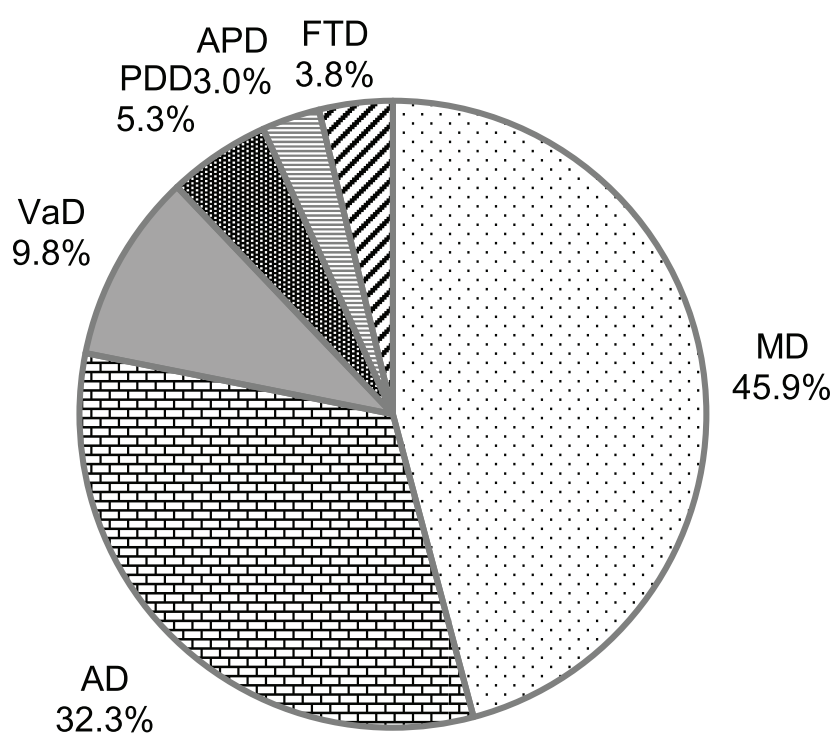

Figure 2 Dementia types prevalence in geriatric ward patients.

Abbreviations: AD, Alzheimer's disease; APD, dementia in atypical parkinsonism; FTD, frontotemporal dementia; PDD, dementia in Parkinson's disease; $\mathrm{VaD}$, vascular dementia.

common was cholinesterase inhibitor (ChE-I), used in $29.5 \%$ of dementia cases. Memantine- N-methyl-D-aspartate (NMDA) receptor antagonist was reported less frequently. It was used as a single anti-dementia agent or in combination with ChE-I. The percentage of dementia cases treated with any anti-dementia medication increased significantly to $74.0 \%$, mainly due to the significant increase in a prescription for ChE-I. Incorrect diagnosis of dementia was verified in two cases, which resulted in cognitive enhancers discontinuation.

\section{Other Psychotropic Medications Taken Before Hospitalization}

Patients who were diagnosed with dementia were significantly more often on anti-depressants at admission $(45.5 \%$ versus $29.6 \%$ in the non-dementia group, $\mathrm{P}=0.002$ ) - Table 3. Selective serotonin/serotonin-noradrenalin reuptake inhibitors were the most frequently used anti-depressants in the whole study group, and they were significantly more often prescribed to dementia patients. Mianserin or other groups of anti-depressants were used less often. Dementia patients significantly more often than the nondementia group were on antipsychotics at admission $(36.4 \%$ versus $7.3 \%$ in the non-dementia group, $\mathrm{P}<0.001$ ), and quetiapine was the most frequently used neuroleptic. Haloperidol, promazine, risperidone, sulpiride, or other antipsychotic medications were used less frequently, and the first two were used significantly more often in dementia sufferers. In 6 cases $(1.4 \%)$, two or three different neuroleptics were used simultaneously. In the case of patients with dementia, those diagnosed before admission to the hospital were significantly more likely to be on anti-depressants and neuroleptics (64.9\% versus $37.9 \%, \mathrm{P}=0.006$; and $54.1 \%$ versus $29.5 \%, \mathrm{P}=0.02$, respectively; Figure 4). Nevertheless, these data suggest that about a third of dementia cases were overlooked by their regular doctors and treated as depression or psychosis. There were no significant differences observed in the use of anxiolytics/hypnotics, anticonvulsants, psychostimulants/nootropics, and antivertigo medications.

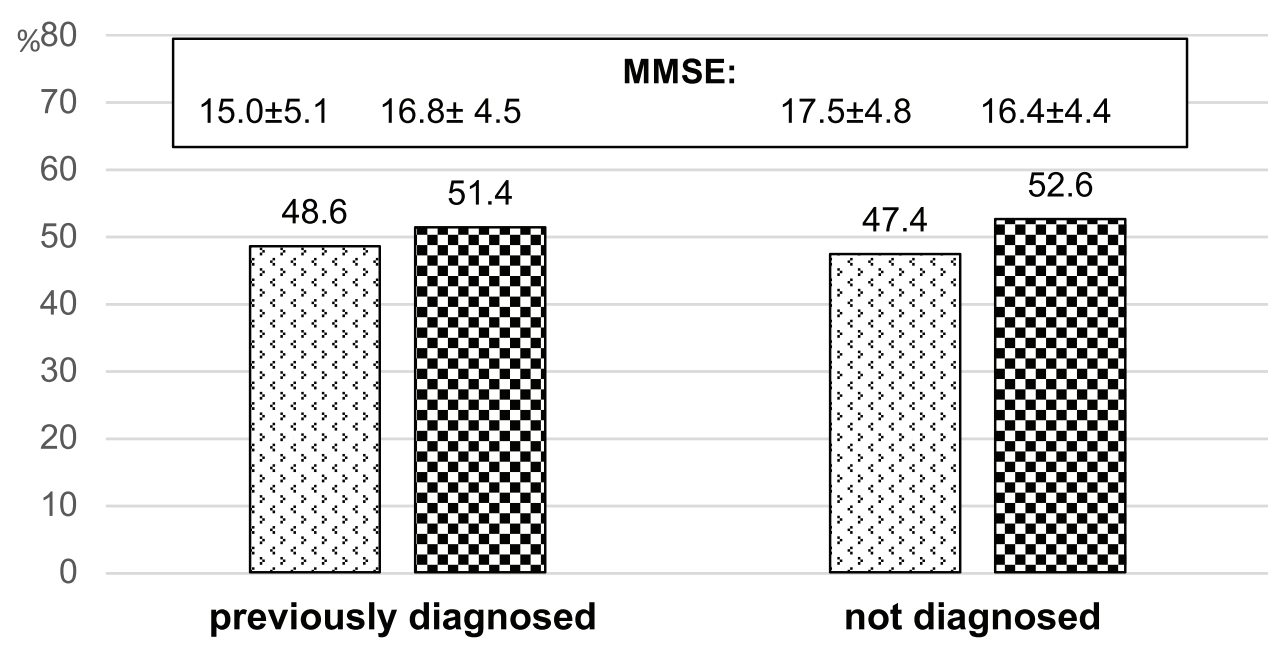

$\square$ dementia as the main ICD-10 in the referral $\square$ no dementia in the referral

Figure 3 MMSE results depending on the previous diagnosis and ICD-I0 code of dementia on referral documents.

Abbreviation: MMSE, Mini-Mental State Examination; ICD-I0, International Statistical Classification of Diseases and Related Health Problems-I0th Revision. 
Table 2 Anti-Dementia Medications (N06D) at Admittance and at Discharge from the Department

\begin{tabular}{|c|c|c|c|c|}
\hline & \multirow[t]{2}{*}{ Total $n=406$} & \multicolumn{2}{|l|}{ Dementia } & \multirow[t]{2}{*}{$P$ value ${ }^{a}$} \\
\hline & & Yes $n=132$ & No $n=274$ & \\
\hline \multicolumn{5}{|l|}{ At admittance } \\
\hline Any & 46 (II.3) & $44(33.3)$ & $2(0.7)$ & $<0.001$ \\
\hline ChE-I (Any) & $4 I(10.1)$ & $39(29.5)$ & $2(0.7)$ & $<0.001$ \\
\hline Donepezil & $26(6.4)$ & $24(18.2)$ & $2(0.7)$ & $<0.001$ \\
\hline Rivastigmine & $15(3.7)$ & I5 (II.4) & - & $<0.001$ \\
\hline Memantine & $14(3.4)$ & $13(9.8)$ & I (0.4) & $<0.001$ \\
\hline ChE-I and memantine & $9(2.2)$ & $8(6.1)$ & $\mathrm{I}(0.4)$ & $<0.001$ \\
\hline \multicolumn{5}{|l|}{ At discharge } \\
\hline Any & $94(24.0)$ & $94(74.0)$ & - & $<0.001$ \\
\hline ChE-I (Any) & $93(23.3)$ & $93(71.0)$ & - & $<0.001$ \\
\hline Donepezil & $52(12.7)$ & $52(39.4)$ & - & $<0.001$ \\
\hline Rivastigmine & $41(10.0)$ & $4 I(3 I . I)$ & - & $<0.001$ \\
\hline Memantine & $19(4.8)$ & $19(14.5)$ & - & 0.17 \\
\hline ChE-I and memantine & $9(2.3)$ & $9(6.9)$ & - & $<0.001$ \\
\hline
\end{tabular}

Notes: Data are $\mathrm{n}(\%) .{ }^{\text {a }}$ Wilcoxon signed-rank test. In all analyses, a two-tailed $\mathrm{P}$ value of less than 0.05 was regarded as significant. Abbreviation: ChE-I, cholinesterase inhibitor.

\section{Discussion}

In the present study, 1/3 of the people hospitalized in the geriatric ward were diagnosed with dementia. This frequency was much higher than in the earlier studies conducted in the community-dwelling older people in Poland or other countries. ${ }^{19,31-33}$ In Gabrylewicz et al's study, agespecific prevalence of dementia in the age-groups $65-69$, $70-74,75-79,80-84$ was $1.9 \%, 5.8 \%, 8.6 \%$, and $16.5 \%$, respectively. ${ }^{19}$ Dementia prevalence in the geriatric ward was rather very similar to those observed in more disabled populations, with similar characteristics to the cohort of older people described in this study (in receipt of formal home care in North Dublin, ${ }^{34}$ or in nursing home residents in Germany). ${ }^{35}$ One of the reasons could be that the need for cognitive dysfunction assessment is one of the causes for referral to the geriatric ward in some cases, as it was shown in the current study. Whereas by the National Health Fund in Poland guidelines, people over 60 can be treated in the geriatric ward, the majority of hospitalized patients were over 75 years of age. The criterion of referral to this ward is not the calendar age itself, but the specificity of patients' health problems. Most of them are people with multiple chronic diseases, polypharmacy, and a high prevalence of geriatric syndromes (including dementia). More advanced age is a crucial risk factor for these. Contrary to other studies, men were considerably more often dementia sufferers. One of the potential explanations could be the high prevalence of Parkinson's disease and parkinsonism in the study group, as some studies confirmed that male sex was a predictor of cognitive decline in parkinsonian patients. ${ }^{36}$

In contrast to the other studies' results, suggesting that Alzheimer's disease is the most common cause of dementia,${ }^{37}$ this type of dementia was only the second most common type in the current study, after the mixed one, observed in $46 \%$ of cases. It could be explained at least partially by the participants' health profiles. They were burdened with cardiovascular disorders, diabetes, and chronic kidney disease. A history of cerebral stroke - a well-known risk factor for cognitive decline - was reported in people with dementia twice as often as in the control group, and Parkinson's disease/syndrome was three times more frequent than in the control group. On the other hand, studies carried out in recent years indicated that in most cases of dementia we dealt with overlapping of primary degenerative pathology and vascular background, ${ }^{38}$ and vascular cognitive impairment is a common contributor to cognitive impairment in later life. ${ }^{39}$ Moreover, the results of some studies have shown that the lack of neuroimaging assessment might lead to clinical overdiagnosis of Alzheimer's disease and the underdiagnoses of vascular pathology. ${ }^{40}$ Every patient diagnosed with dementia had a CT scan, which may have also contributed to such results.

The study confirmed that as many as $72 \%$ of older adults living with dementia were not formally diagnosed before admission and - as a consequence - did not receive any anti-dementia medications. Memory problems or 
Table 3 Psychotropic Medications at Admittance to the Department

\begin{tabular}{|c|c|c|c|c|}
\hline & \multirow[t]{2}{*}{ Total $n=406$} & \multicolumn{2}{|l|}{ Dementia } & \multirow[t]{2}{*}{ P value ${ }^{a}$} \\
\hline & & Yes $n=132$ & No $n=274$ & \\
\hline \multicolumn{5}{|l|}{ Anti-depressants (N06A) } \\
\hline Any & |4| (34.7) & $60(45.5)$ & $81(29.6)$ & 0.002 \\
\hline SSRI/SNRI & II 5 (28.3) & $53(40.2)$ & $62(22.6)$ & $<0.001$ \\
\hline Mianserin & $37(9.1)$ & II (8.3) & $26(9.5)$ & 0.85 \\
\hline Other ${ }^{b}$ & II (2.6) & $4(3.0)$ & $7(2.5)$ & 0.75 \\
\hline \multicolumn{5}{|l|}{ Antipsychotics (N05A) } \\
\hline Any & $68(16.7)$ & $48(36.4)$ & $20(7.3)$ & $<0.001$ \\
\hline Quetiapine & $49(12.1)$ & $34(25.8)$ & $15(5.5)$ & $<0.001$ \\
\hline Haloperidol & $9(2.2)$ & $8(6.1)$ & $\mathrm{I}(0.4)$ & 0.001 \\
\hline Promazine & $8(2.0)$ & $7(5.3)$ & $\mathrm{I}(0.4)$ & 0.002 \\
\hline Risperidone & $2(0.5)$ & $2(1.5)$ & - & 0.12 \\
\hline Sulpiride & $6(1.5)$ & $\mathrm{I}(0.8)$ & $5(1.8)$ & 0.67 \\
\hline Other ${ }^{c}$ & $4(1.1)$ & $2(1.5)$ & $2(0.7)$ & 0.60 \\
\hline \multicolumn{5}{|c|}{ Anxiolytics(N05B)/Hypnotics (N05C) } \\
\hline Any & $68(16.8)$ & $22(16.7)$ & $46(16.8)$ & 1.00 \\
\hline Hydroxyzine & $32(7.9)$ & $13(9.8)$ & $19(7.0)$ & 0.33 \\
\hline Benzodiazepines/hypnotics & $45(11.1)$ & II (8.3) & $34(12.4)$ & 0.24 \\
\hline \multicolumn{5}{|l|}{ Anticonvulsants (N03) } \\
\hline Valproic acid & II (2.7) & $5(3.8)$ & $6(2.2)$ & 0.35 \\
\hline \multicolumn{5}{|c|}{ Psychostimulants/nootropics (N06BX) } \\
\hline Any & $86(21.2)$ & $34(25.8)$ & $52(19.0)$ & 0.12 \\
\hline Piracetam & $35(8.6)$ & $12(9.1)$ & $23(8.4)$ & 0.85 \\
\hline Vinpocetine & $63(15.5)$ & $26(19.7)$ & $37(13.5)$ & 0.11 \\
\hline Ginkgo folium (N06D) & $2(0.5)$ & $\mathrm{I}(0.8)$ & $\mathrm{I}(0.4)$ & 0.55 \\
\hline \multicolumn{5}{|l|}{ Antivertigo (N07) } \\
\hline Any & $23(5.7)$ & $7(5.3)$ & $16(5.8)$ & 1.0 \\
\hline Cinnarizine & $5(1.2)$ & $\mathrm{I}(0.8)$ & $4(1.5)$ & 1.0 \\
\hline Betahistine & $19(4.7)$ & $6(4.5)$ & $13(4.7)$ & 1.0 \\
\hline \multicolumn{5}{|l|}{ Peripheral vasodilators (C04A) } \\
\hline Any & $28(6.9)$ & $8(6.1)$ & $20(7.3)$ & 0.84 \\
\hline Nicergoline & $8(2.0)$ & - & $8(2.9)$ & 0.06 \\
\hline Pentoxifylline & $15(3.7)$ & $8(6.1)$ & $7(2.6)$ & 0.09 \\
\hline Bencyclane & $8(2.0)$ & I (0.8) & $7(2.6)$ & 0.45 \\
\hline \multicolumn{5}{|l|}{ Lipid modifying agents (CIOA) } \\
\hline HMG-CoA reductase inhibitors & $142(35.0)$ & $4 I(3 I .1)$ & $101(36.9)$ & 0.27 \\
\hline
\end{tabular}

Notes: Data are $\mathrm{n}(\%){ }^{a} \chi^{2}$ test. In all analyses, a two-tailed $\mathrm{P}$ value of less than 0.05 was regarded as significant. ${ }^{\mathrm{b}}$ doxepin-5; opipramol-2; mirtazapine-2, trazodone-2, amitriptyline-I; tianeptine-I; 'chlorprotixen-2, tiapridal-I, fluanxol-I; in 8 (2\%) patients- two different antipsychotic medications and in one case- three different neuroleptics were used at the same time.

Abbreviations: HMG-CoA, 3-hydroxy-3-methylglutaryl coenzyme A; SNRI, serotonin-norepinephrine reuptake inhibitor; SSRI, selective serotonin reuptake inhibitor.

behavioral disturbances were observed in $82.4 \%$ of them and $50 \%$ of them had moderate cognitive deterioration. However, only in $47.4 \%$ of these cases dementia was suspected by a doctor referring the patient to the geriatric department. Thus, for 50 patients $37.9 \%$ of dementia cases), the treating physicians were unaware of the problem, although the MMSE score in these patients was similar to the observed in diagnosed cases. Similar results were achieved in elderly patients admitted to a post-acute rehabilitation facility in Lausanne, Switzerland.$^{37}$ Not diagnosing dementia or detecting dementia in its later stage is raised in the literature..$^{8,10-12}$ It can be due to various 


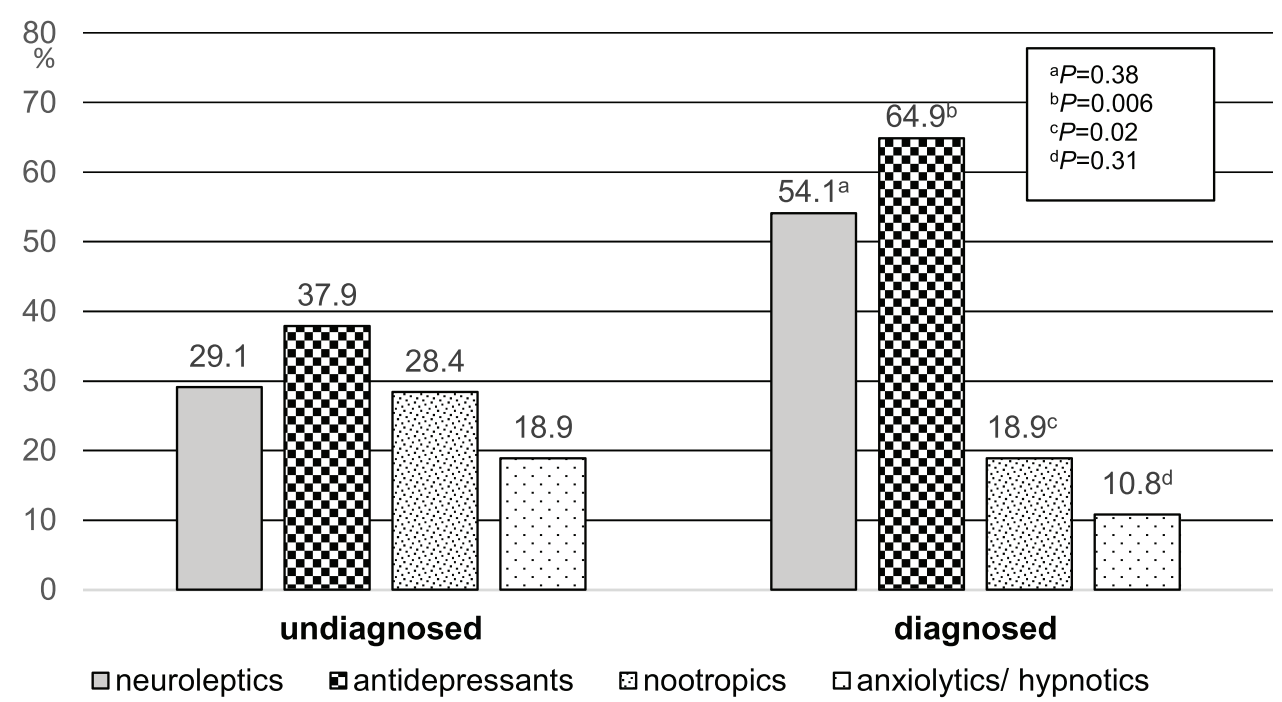

Figure 4 Use of different groups of psychotropic medications in demented patients (detected and undetected before hospitalization).

reasons. ${ }^{11}$ One-third of the people admitted to the ward lived alone. It was significantly less common in people with dementia, although the percentage of people living alone in this group was still high and amounted to $22.7 \%$ in the current study. In the case of infrequent or superficial contacts with family members, this may delay making the correct diagnosis. As confirmed in some studies, people with undiagnosed dementia tend to visit the doctor without an accompanying person, making it impossible to interview an independent informant. ${ }^{11}$ They may also be concerned about disclosing their diagnosis as it can affect their whole life and the attitude of their family and others. ${ }^{41}$ Assessment of cognitive functions in elderly patients - although recommended by geriatricians - has not entered the daily practice of family doctors in Poland, and international guidelines do not recommend universal screening for dementia. ${ }^{42}$ Hence, most cases of dementia are diagnosed only in their moderate phase, when behavioral disturbances attract the attention of people from the patient's environment. ${ }^{43}$ It can have important implications both for patients and for their families connected with risks and complications of cognitive disability. ${ }^{15,16,44}$ The study results suggest the need to address the problem of dementia in public media or through healthcare campaigns, as part of a more global dementia action plan. ${ }^{7,45}$ This could raise dementia awareness and reduce dementia stigma in Poland.

Limited financial availability of anti-dementia drugs can also influence dementia treatment. In Poland, partial, $70 \%$ reimbursement of pharmacotherapy costs in the study period covered only drugs from the ChE-I group. The patient bore the full cost of the memantine treatment. It could have contributed to the fact that it was used relatively rarely in this group. In 2017, the Ministry of Health launched the "Medications for 75" project in Poland. ChEI found a place on the reimbursement lists that included prescription drugs for people over 75 , free of charge; unfortunately, memantine remained a non-reimbursed drug. Although the change should influence dementia treatment in Poland, awareness of the importance of cognitive assessment in geriatric patients seems to be the prevailing factor. The propensity to perform such an assessment depends on financial incentives for family doctors. ${ }^{12}$ The diagnosed type of dementia is another factor that can influence the treatment with cognitive enhancers. In $\mathrm{AD}, \mathrm{ChE}-\mathrm{Is}$ and memantine are recommended. They may also be considered for the treatment of vascular cognitive impairment and in selected parkinsonian patients. ${ }^{13,46}$ But in Poland, donepezil treatment is reimbursed only in AD, Lewy Body dementia, and PDD, whereas rivastigmine is reimbursed only in AD. Finally, it should also be taken into account that drugs used in dementia have no causal effect but act only symptomatically. Their effectiveness is limited, may change over time, or side effects may prevent their use in some patients. ${ }^{13}$ This can also affect their prescribing, and high rates of non-persistence in dementia patients who received a prescription for cognitive enhancers. Research carried out in Germany, for example, showed that only $69.9 \%$ of patients aged $>70$ who received a prescription for anti-dementia medication were on it six months after initiation of treatment, and only $56.2 \%$ after 12 months. ${ }^{47}$ 
The study confirmed other authors' findings that different psychotropic drug use in patients with dementia remains high. ${ }^{48}$ Before admission to the department, they received anti-depressants and antipsychotics significantly more often than non-dementia patients. Both groups of medications were prescribed significantly more frequently in dementia detected before hospitalization. It may indicate that in the group of dementia earlier detected behavioral disorders and psychotic symptoms were more common. Maybe also physicians found it easier to prescribe psychotropic drugs when they knew that the patient had dementia. On the other hand, the results of different studies indicate depression and anxiety disorders as a possible cause or prodromal symptoms of dementia. ${ }^{49,50}$

The study results should be interpreted with caution as it has some limitations that should be mentioned. It was carried out not on a randomly selected representative sample of the older population but among patients hospitalized in the geriatrics department. Its results can be generalized only to similar patients groups, not to the general Polish older population. It was also based on a secondary analysis of data previously collected (during the routine geriatric evaluation of admitted patients- "usual practice" study). Therefore, data on some variables - such as MMSE scores - were not available for all patients, as indicated in Table 1.

\section{Conclusions}

In summary, dementia affects a significant percentage of patients in the geriatric ward. The majority of its cases are diagnosed only during a patient's hospital stay. It is in part due to the lack of systematic cognitive assessment in primary care settings, although other factors can play a role.

\section{Acknowledgments}

The author appreciates very much the involvement of Dr. Agnieszka Kasiukiewicz in data collection and creating the database.

\section{Funding}

This research did not receive any specific grant from funding agencies in the public, commercial, or not-forprofit sectors. The source study was supported by the Medical University of Bialystok, grant number N/ST/ZB/ $15 / 001 / 3301$. The financial sponsor played no role in the design, execution, analysis and interpretation of data.

\section{Disclosure}

The author reports no conflicts of interest for this work.

\section{References}

1. van Roessel S, Keijsers C, Romijn MDM. Dementia as a predictor of morbidity and mortality in patients with delirium. Maturitas. 2019;125:63-69. doi:10.1016/j.maturitas.2019.03.005

2. Duckett L. Alzheimer's dementia: morbidity and mortality. J Insur Med. 2001;33(3):227-234.

3. Gaugler JE, Duval S, Anderson KA, Kane RL. Predicting nursing home admission in the U.S: a meta-analysis. BMC Geriatrics. 2007;7 (1):13. doi:10.1186/1471-2318-7-13

4. Wancata J, Freidl M, Unger A, et al. [Projections about the future number of dementia sufferers: increasing life expectancy not sufficiently considered?]. Psychiatr Danub. 2015;27(4):452-457.

5. Wittenberg R, Hu B, Jagger C, et al. Projections of care for older people with dementia in England: 2015 to 2040. Age Ageing. 2020;49 (2):264-269.

6. Jacqmin-Gadda H, Alperovitch A, Montlahuc C, et al. 20-Year prevalence projections for dementia and impact of preventive policy about risk factors. Eur J Epidemiol. 2013;28(6):493-502.

7. Prince MJ, Wimo A, Guerchet MM, Ali GC. World Alzheimer Report 2015 - the Global Impact of Dementia: An Analysis of Prevalence, Incidence, Cost and Trends. London: Alzheimer's Disease International; 2015.

8. Connolly A, Gaehl E, Martin H, Morris J, Purandare N. Underdiagnosis of dementia in primary care: variations in the observed prevalence and comparisons to the expected prevalence. Aging Ment Health. 2011;15(8):978-984.

9. Cherubini A, Ruggiero C, Dell'Aquila G, et al. Underrecognition and undertreatment of dementia in Italian nursing homes. $J$ Am Med Dir Assoc. 2012;13(8):759e 757-713.

10. Nakamura AE, Opaleye D, Tani G, Ferri CP. Dementia underdiagnosis in Brazil. Lancet. 2015;385(9966):418-419. doi:10.1016/S01406736(15)60153-2

11. Amjad H, Roth DL, Sheehan OC, Lyketsos CG, Wolff JL, Samus QM. Underdiagnosis of Dementia: an Observational Study of Patterns in Diagnosis and Awareness in US Older Adults. $J$ Gen Intern Med. 2018;33(7):1131-1138. doi:10.1007/s11606-018-4377-y

12. Mason A, Liu D, Kasteridis $P$, et al. Investigating the impact of primary care payments on underdiagnosis in dementia: A difference-in-differences analysis. Int $J$ Geriatr Psychiatry. 2018;33 (8):1090-1097. doi:10.1002/gps.4897

13. Ismail Z, Black SE, Camicioli R, et al. Recommendations of the 5th Canadian Consensus Conference on the diagnosis and treatment of dementia. Alzheimers Dement. 2020;16(8):1182-1195. doi:10.1002/ alz. 12105

14. Kane RL, Ouslander JG, Resnick B, Malone ML. Essentials of Clinical Geriatrics. Eighth ed. New York: McGraw-Hill Education; 2018.

15. Borson S, Frank L, Bayley PJ, et al. Improving dementia care: the role of screening and detection of cognitive impairment. Alzheimers Dement. 2013;9(2):151-159. doi:10.1016/j.jalz.2012.08.008

16. Vetillard AL, Grandcollot L, Lechowski L, et al. [First year prognosis of patients hospitalized in an acute geriatric ward with a known dementia or newly diagnosed]. Geriatr Psychol Neuropsychiatr Vieil. 2013;11(1):43-48.

17. Bledowski P, Mossakowska M, Chudek J, et al. Medical, psychological and socioeconomic aspects of aging in Poland: assumptions and objectives of the PolSenior project. Exp Gerontol. 2011;46(12):10031009. doi:10.1016/j.exger.2011.09.006

18. Mossakowska M, Wiecek A, Bledowski P, eds. Polsenior. Medical, Psychological, Sociological and Economic Aspects of the Aging of People in Poland. Poznan: Termedia Wydawnictwa Medyczne; 2012. 
19. Gabryelewicz T. [The prevalence of dementia in the population of the Warsaw district of Mokotow from 65 to 84 years of age]. Psychiatr Pol. 1999;33(3):353-366.

20. Wojszel ZB, Kasiukiewicz A, Health ML. Functional Determinants of Orthostatic Hypotension in Geriatric Ward Patients: A Retrospective Cross Sectional Cohort Study. J Nutr Health Aging. 2019;23(6):509-517.

21. Hodkinson HM. Evaluation of a mental test score for assessment of mental impairment in the elderly. Age Ageing. 1972;1(4):233-238. doi:10.1093/ageing/1.4.233

22. Folstein MF, Folstein SE, McHugh PR. "Mini-mental state". A practical method for grading the cognitive state of patients for the clinician. J Psychiatr Res. 1975;12(3):189-198. doi:10.1016/0022-3956 (75)90026-6

23. Mungas D, Marshall SC, Weldon M, Haan M, Reed BR. Age and education correction of Mini-Mental State Examination for Englishand Spanish-speaking elderly. Neurology. 1996;46(3):700-706. doi:10.1212/WNL.46.3.700

24. World Health O. The ICD-10 Classification of Mental and Behavioural Disorders: Diagnostic Criteria for Research. Geneva: World Health Organization; 1993.

25. Cummings JL, Dubois B, Molinuevo JL, Scheltens P. International Work Group criteria for the diagnosis of Alzheimer disease. Med Clin North Am. 2013;97(3):363-368. doi:10.1016/j.mcna.2013.01.001

26. Mahoney FI, Barthel DW. Functional Evaluation: the Barthel Index. Md State Med J. 1965;14:61-65.

27. Fillenbaum GG, Smyer MA. The development, validity, and reliability of the OARS multidimensional functional assessment questionnaire. J Gerontol. 1981;36(4):428-434. doi:10.1093/geronj/36.4.428

28. Rockwood K, Song X, MacKnight C, et al. A global clinical measure of fitness and frailty in elderly people. CMAJ. 2005;173(5):489-495.

29. Nickel J, Gohlke B-O, Erehman J, et al. SuperPred: update on drug classification and target prediction. Nucleic Acids Res. 2014;42(W1): W26-W31. doi:10.1093/nar/gku477

30. Dunkel M, Gunther S, Ahmed J, Wittig B, Preissner R. SuperPred: drug classification and target prediction. Nucleic Acids Res. 2008;36 (Web Server):W55-W59. doi:10.1093/nar/gkn307

31. Wertman E, Brodsky J, King Y, Bentur N, Chekhmir S. An estimate of the prevalence of dementia among community-dwelling elderly in Israel. Dementia and Geriatric Cognitive Disorders. 1996;46(3):294299. doi:10.1159/000107593

32. De Deyn PP, Goeman J, Vervaet A, Dourcy-Belle-Rose B, Van Dam D, Geerts E. Prevalence and incidence of dementia among 75-80year-old community-dwelling elderly in different districts of Antwerp, Belgium: the Antwerp Cognition (ANCOG) Study. Clin Neurol Neurosurg. 2011;113(9):736-745.

33. Yusuf AJ, Baiyewu O, Sheikh TL, Shehu AU. Prevalence of dementia and dementia subtypes among community-dwelling elderly people in northern Nigeria. Int Psychogeriatr. 2011;23(3):379-386.

34. O’Brien I, Smuts K, Fan CW, O’Sullivan M, Warters A. High prevalence of dementia among community dwelling older adults in receipt of state funded home care packages: implications for health care planning. Ir J Psychol Med. 2019;36(2):139-144.
35. Hoffmann F, Kaduszkiewicz H, Glaeske G, van den Bussche H, Koller D. Prevalence of dementia in nursing home and communitydwelling older adults in Germany. Aging Clin Exp Res. 2014;26 (5):555-559.

36. Cholerton B, Johnson CO, Fish B, et al. Sex differences in progression to mild cognitive impairment and dementia in Parkinson's disease. Parkinsonism Relat Disord. 2018;50:29-36.

37. Ferretti M, Seematter-Bagnoud L, Martin E, Bula CJ. New diagnoses of dementia among older patients admitted to postacute care. $\mathrm{J} \mathrm{Am}$ Med Dir Assoc. 2010;11(5):371-376.

38. Schneider JA, Arvanitakis Z, Bang W, Bennett DA. Mixed brain pathologies account for most dementia cases in community-dwelling older persons. Neurology. 2007;69(24):2197-2204.

39. Gorelick PB, Nyenhuis D. Understanding and treating vascular cognitive impairment. Continuum. 2013;19(2Dementia):425-437.

40. Caixeta L, Soares VL, Soares CD. Absence of MRI exams in epidemiological studies can leads to clinical overdiagnosis of Alzheimer's disease and underdiagnosis of vascular dementia. Arq Neuropsiquiatr. 2009;67(2A):369-370.

41. Bhatt J, Ruffell TO, Scior K, Charlesworth G. "Who to Tell, How and When?": development and Preliminary Feasibility of an Empowerment Intervention for People Living with Dementia Who are Fearful of Disclosing Their Diagnosis. Clin Interv Aging. 2020;15:1393-1407.

42. Moyer VA, Force USPST. Screening for cognitive impairment in older adults: U.S. Preventive Services Task Force recommendation statement. Ann Intern Med. 2014;160(11):791-797.

43. Pietrzak K, Wojszel ZB. Trudnoœci w terapii cukrzycy u pacjenta geriatrycznego $z$ otępieniem-opis przypadku Difficulties of the diabetes treatment in a geriatric patient with a diagnosed dementia-a case study. Gerontologia Polska. 2018;2.

44. Amjad H, Roth DL, Samus QM, Yasar S, Wolff JL. Potentially Unsafe Activities and Living Conditions of Older Adults with Dementia. J Am Geriatr Soc. 2016;64(6):1223-1232.

45. Kostev K. People with dementia campaign to be better understood by public. Nurs Older People. 2010;22(3):4.

46. Otero JL. Dementia with Parkinson disease: clinical diagnosis, neuropsychological aspects and treatment. Dement Neuropsychol. 2008;2 (4):261-266.

47. Bohlken J, Jacob L, Kostev K. Association between Anti-Dementia Treatment Persistence and Daily Dosage of the First Prescription: A Retrospective Analysis in Neuropsychiatric Practices in Germany. $J$ Alzheimers Dis. 2017;58(1):37-44.

48. Bonin-Guillaume S, Martin G, Zafack J, et al. [Antipsychotic use in the cohort PACA-Alz in patients with Alzheimer's disease and other dementia in 2010]. Article in French. Therapie. 2014;69(3):213-222.

49. Santabarbara J, Villagrasa B, Gracia-Garcia P. Does depression increase the risk of dementia? Updated meta-analysis of prospective studies. Actas Esp Psiquiatr. 2020;48(4):169-180.

50. Santabarbara J, Lipnicki DM, Villagrasa B, Lobo E, Lopez-Anton R. Anxiety and risk of dementia: systematic review and meta-analysis of prospective cohort studies. Maturitas. 2019;119:14-20.
Clinical Interventions in Aging

\section{Publish your work in this journal}

Clinical Interventions in Aging is an international, peer-reviewed journal focusing on evidence-based reports on the value or lack thereof of treatments intended to prevent or delay the onset of maladaptive correlates of aging in human beings. This journal is indexed on PubMed Central, MedLine, CAS, Scopus and the Elsevier
Bibliographic databases. The manuscript management system is completely online and includes a very quick and fair peer-review system, which is all easy to use. Visit http://www.dovepress.com/ testimonials.php to read real quotes from published authors. 